\title{
MODELAGEM DA ESTEIRA TURBULENTA A JU- SANTE DE UMA TURBINA EÓLICA SIMULADA A PARTIR DE UMA ZONA PERMEÁVEL
}

\author{
L. J. L. STIVAL ${ }^{1}$, J. M. VEDOVOTO ${ }^{2}$, F. O. ANDRADE $^{3}$ \\ ${ }^{1}$ Universidade Federal do Paraná, Programa de Pós-Graduação em Engenharia de \\ Recursos Hídricos e Ambiental \\ ${ }^{2}$ Universidade Federal de Uberlândia, Departamento de Engenharia Mecânica \\ ${ }^{3}$ Universidade Tecnológica Federal do Paraná, Departamento de Construção Civil \\ Email para contato: leandro.stival@ufpr.br \\ RESUMO - A energia eólica cresceu significativamente no Brasil na última dé- \\ cada, porém a eficiência de geração eólica ainda é baixa. Por este motivo é \\ importante estudos a fim de aumentar o poder de geração de maneira viável ao \\ mercado. Este estudo visa modelar a esteira turbulenta gerada a jusante de um \\ aerogerador, onde a turbina eólica foi modelada com base na teoria do disco \\ atuador, aplicando RANS com modelo de turbulência $k$ - $\epsilon$ de baixo custo com- \\ putacional. Os resultados demonstraram uma grande perda de energia cinética \\ inicial em baixas velocidades de entrada, porém com alto nível de recuperação \\ de velocidade ao final da esteira turbulenta.
}

\section{INTRODUÇÃO}

A energia eólica ganhou visibilidade na última década em termos de progresso e potencial, principalmente no Brasil. O mercado brasileiro de energia eólica já avançou significativamente, o país continha 1,5 GW de capacidade instalada no ano de 2011 para 13 GW no início de 2018,o qual representa um enorme crescimento cumulativo (ABEEólica, 2018; GWEC, 2014). A quantidade de energia gerada em um parque eólico não depende somente da disponibilidade de vento, mas também das características do padrão de vento que está sendo fornecida. Por isso, é essencial estudar a eficiência na geração de energia eólica, avaliando os efeitos de determinados parâmetros e coeficientes relacionados ao vento que incide na turbina eólica. Portanto, uma avaliação criteriosa dos recursos eólicos é desejável ao desenvolvimento de um projeto eólico efetivo.

Um dos grandes empecilhos de um projeto eólico eficiente está relacionado com a produção de esteiras turbulentas, que são áreas de escoamentos com quantidade de movimento reduzida e turbulência aumentada. O desenvolvimento da esteira turbulenta certamente afeta a potência de geração e, por isso, é essencial que os desenvolvedores de plantas eólicas sejam capazes de quantificar e qualificar a magnitude das incertezas e características do escoamento a jusante da turbina (Mo et al., 2013; Vermeer et al., 2003).

Neste contexto, nos projetos de grande parques eólicos a modelagem numérica ou experimental do escoamento ao redor das turbinas tornam-se extremamente relevantes para otimização do rendimento energético. Uma grande parte das simulações de interesse prático é realizada mediante a resolução numérica das equações médias de Navier-Stokes, conhecidas como equações RANS (Reynolds Average Navier-Stokes), derivadas dos pressupostos fundamentais da conservação de massa e quantidade do movimento. 


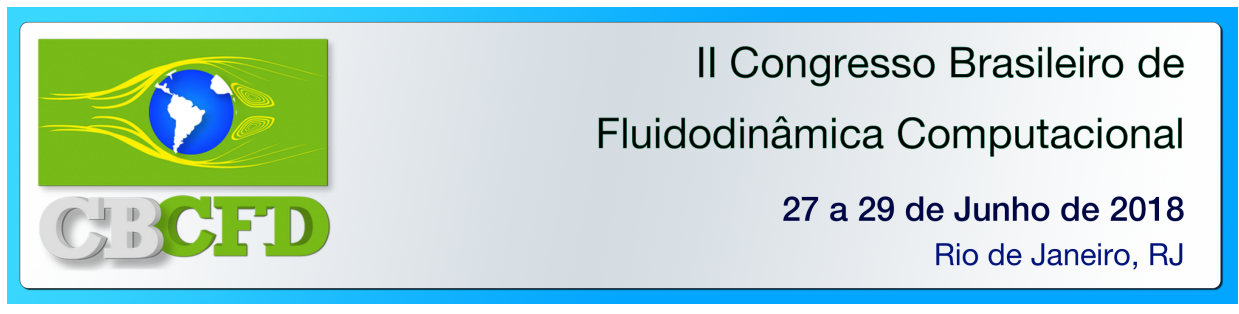

\section{METODOLOGIA}

Neste trabalho, as simulações numéricas do escoamento foram realizadas usando a metodologia RANS com o modelo de turbulência $k-\epsilon$, disponível na versão acadêmica do software comercial ANSYS Fluent (ANSYS Inc., 2017). A representação da turbina eólica foi obtida através de uma metodologia simplificada com base na teoria do disco atuador. A teoria base da aerodiâmica do rotor é estruturada a partir da conservação da quantidade do movimento pelo elemento de pá de Betz, o qual modela um escoamento unidimensional ideal através do disco rotor. O modelo da turbina eólica é baseado na configuração de um disco esponojoso que consiste num volume permeável, sendo que o escoamento através deste é calculado pelo gradiente de pressão logo a montante e a jusante do aerogerador modelado pelo disco permeável. A formulação utilizada é aquela proposta por Çengel e Cimbala (2013) e disponível no software ANSYS Fluent (ANSYS Inc., 2017).

As simulações foram realizadas com uma malha bi-dimensional contendo 380265 nós, possuindo $2000 \mathrm{~m}$ de comprimento longitudinal e $700 \mathrm{~m}$ de largura. O zona esponjosa que representa o rotor da turbina está localizado a $500 \mathrm{~m}$ a jusante da condição de contorno de entrada, tendo medidas de $2 \times 100 \mathrm{~m}$ e uma área total de $400 \mathrm{~m}^{2}$ como representado na Figura 1.

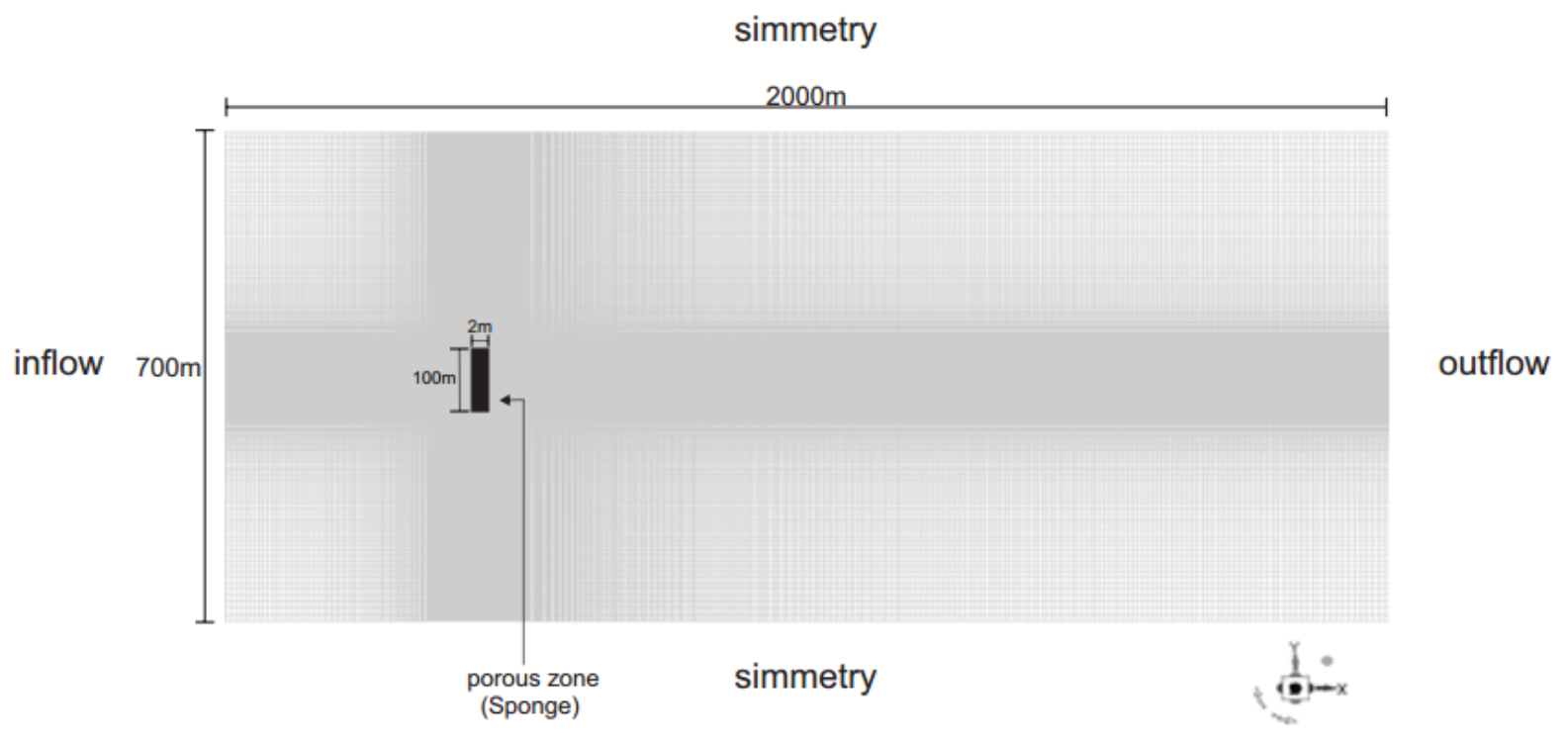

Figura 1 - Malha da simulção da esteira turbulenta

A zona esponjosa representando a turbina eólica é simulada pela opção de zona porosa do ANSYS Fluent, onde as condições de escoamento são baseadas em três parâmetros principais: (1) permeabilidade média $(\psi),(2)$ coeficiente de gradiente de pressão $\left(C_{2}\right)$ e (3) a espessura média da zona porosa $(\Delta m)$. A zona porosa é aplicada a uma espessura finita, onde o gradiente de pressão é calculado de acordo com a Lei de Darcy com um termo adicional de perda de inércia, sendo definido pela Equação 1 (ANSYS Inc., 2017).

$$
\Delta p=-\left(\frac{\mu}{\Psi} v+C_{2} \frac{1}{2} \rho v^{2}\right) \Delta m
$$


onde $\Delta p$ é o gradiente de pressão, $\mu$ representa a viscosidade do fluido, $\psi$ é a permeabilidade média, $\rho, v$ é a velocidade normal e $\Delta m$ é espessura da porosidade média.

O gradiente de pressão da Equação 1 expressa uma equação de segunda ordem dependente da velocidade de entrada, onde o gradiente aumenta com o desenvolvimento da velocidade. Com isso, os três parâmetros principais elencados acima foram calculados a partir de dados medidos de velocidade do vento e pressão. Os valores encontrados são: $0.00003 \mathrm{~m}^{2}$ para permeabilidade média, $2 \mathrm{~m}$ para espessura da porosidade média e 0.203 $m^{-1}$ para coeficiente de gradiente de pressão.

\section{RESULTADOS}

Os resultados obtidos foram selecionados em relação a velocidade de entrada, variando de $5 \mathrm{~m} / \mathrm{s}$ até $11 \mathrm{~m} / \mathrm{s}$, em intervalos de $2 \mathrm{~m} / \mathrm{s}$. As análises foram elaboradas a partir da subdivisão de dois grupamentos de esteira turbulenta: (1) a seção central com amplitude longitudinal e (2) três seções tranversais detalhadas a 5, 7 e 10 diâmetros de rotor $(D)$ a jusante do aerogerador, representados pela Figura 2.
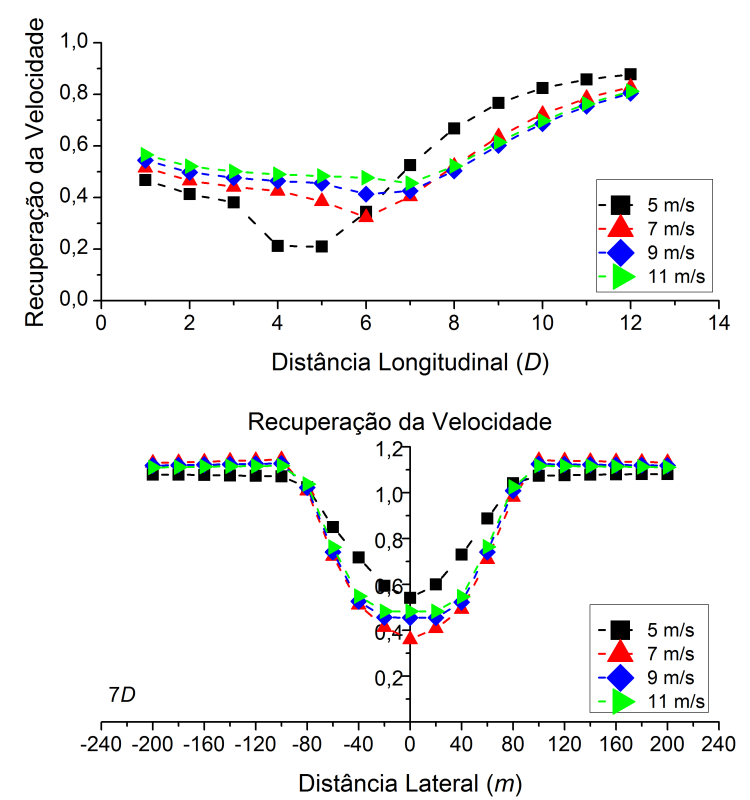
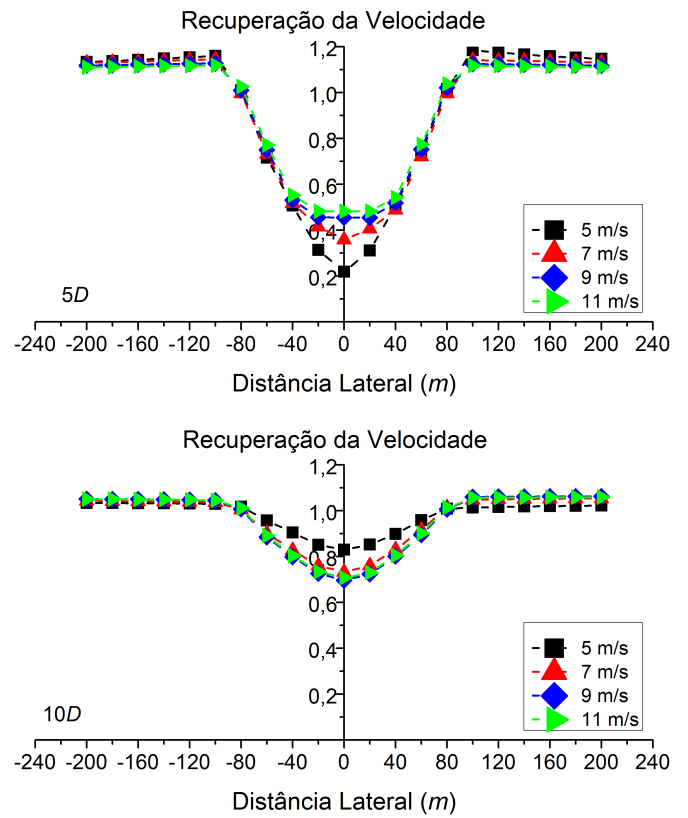

Figura 2 - Recuperação de velocidade na esteira turbulenta: (a) longitudinal na linha central da esteira e nas seções transversais a jusante em $(b) 5,(c) 7,(d) 10 D$.

A Figura 2(a) apresenta a recuperação de velocidade longitudinal na linha de centro da esteira turbulenta. Os resultados mostraram que para o caso de $5 \mathrm{~m} / \mathrm{s}$ houve uma maior perda de energia cinética na região de recirculação do campo próximo a turbina. No caso de $5 \mathrm{~m} / \mathrm{s}$ a recuperação da velocidade nesta região (até $5 \mathrm{D}$ ) foi de $20 \%$, enquanto para as velocidades de 7,9 e $11 \mathrm{~m} / \mathrm{s}$ a recuperção ficou entre 40 a $50 \%$. A partir da distância longitudinal $7 \mathrm{D}$ o comportamento ma recuperação da velocidade foi semelhante para os 
casos de 7, 9 e $11 \mathrm{~m} / \mathrm{s}$, os quais atingiram cerca de $80 \%$ da velocidade de entrada ao final do trecho. Para o caso de $5 \mathrm{~m} / \mathrm{s}$, a recuperação final foi de aproximadamente $90 \%$.

Figura 2(b), Figura 2(c) e Figura 2(d) ilustram a recuperação das velocidades para seções transversais localizadas em $5 D, 7 D$ e $10 D$. Estas figuras reafirmam os resultados da Figura 2(a) em que existe um maior déficit de velocidade na região mais próxima da turbina no caso de $5 \mathrm{~m} / \mathrm{s}$. No entanto, ao final do trecho esse caso apresenta maior recuperação quando comparado as velocidades de 7, 9 e $11 \mathrm{~m} / \mathrm{s}$.

\section{CONCLUSÃO}

Neste estudo foi implementado uma modelagem simplificada da esteira turbulenta gerada a jusante de uma turbina eólica, utilizando o método RANS de fluidodinâmica computacional. Os resultados demonstraram maior déficit de energia cinética para o caso de menor velocidade $(5 \mathrm{~m} / \mathrm{s})$. Ao final do trecho este caso apresentou maior recuperação de velocidade quando comparado aos casos de 7,9 e $11 \mathrm{~m} / \mathrm{s}$.

\section{REFERÊNCIAS}

ABEEÓliCA. Associação brasileira de energia eólica, 2018.

ANSYS InC. ANSYS Fluent-18.2 User Manual, 2017.

GWEC. Global wind energy outlook 2014. Relatório técnico, Global Wind Energy Council, 2014.

Mo, J. O.; Choudhry, A.; Arjomandi, M.; Kelso, R.; Lee, Y. H. Effects of wind speed changes on wake instability of a wind turbine in a virtual wind tunnel using large eddy simulation. Journal of Wind Engineering and Industrial Aerodynamics, 117, 38-56, 2013.

Vermeer, L.; Sørensen, J.; Crespo, A. Wind turbine wake aerodynamics. Progress in Aerospace Sciences, 39, 467-510, 2003.

Çengel, Y.; Cimbala, J. Fluid Mechanics Fundamentals and Applications: Third Edition. McGraw-Hill Higher Education, 2013. 